\title{
On the quantitative relation between dark kinetics of NPQ-induced changes in variable fluorescence and the activation state of the $\mathrm{CF}_{0} \cdot \mathrm{CF}_{1} \cdot \mathrm{ATPase}$ in leaves
}

\author{
W.J. VREDENBERG \\ Department of Plant Physiology, Wageningen University, Droevendaalsesteeg 1, 6708 PB Wageningen, The Netherlands
}

\begin{abstract}
The variable fluorescence at the maximum $\mathrm{F}_{\mathrm{m}}$ of the fluorescence induction (Kautsky) curve is known to be substantially suppressed shortly after light adaption due to nonphotochemical $\mathrm{q}_{\mathrm{E}}$ quenching. The kinetic pattern of the dark decay at $\mathrm{F}_{\mathrm{m}}$ consists of three components with rates $\sim 20, \sim 1$, and $\sim 0.1 \mathrm{~s}^{-1}$, respectively. Light adaptation has no or little effect on these rate constants. It causes a decrease in the ratio between the amplitudes of the slow and fast one with negligible change in the small amplitude of the ultra-slow component. Results add to evidence for the hypothesis that the dark-reversible decrease in variable fluorescence accompanying light adaptation during the $\mathrm{P}-\mathrm{S}$ phase of the fluorescence induction curve is due to an alteration in nonphotochemical $\mathrm{q}_{\mathrm{E}}$ quenching caused by changes in the trans-thylakoid proton motive force in response to changes in the proton conductance $\mathrm{g}_{\mathrm{H}^{+}}$of the $\mathrm{CF}_{0^{-}}$-channel of the $\mathrm{CF}_{0} \cdot \mathrm{CF}_{1} \cdot \mathrm{ATPase}$.
\end{abstract}

Additional key words: $\mathrm{CF}_{0} \cdot \mathrm{F}_{1} \cdot \mathrm{ATPase}$; chlorophyll fluorescence kinetics; nonphotochemical quenching; Kautsky fluorescence induction curve; quenching mechanisms; system analysis.

\section{Introduction}

The photosynthetic process in plants, algae, and bacteria owes its high energetic potential to a flexible, structural, and functional membrane organization (Ke 2001). A variety of multi-subunit protein complexes constituting the photosynthetic apparatus is involved in light harvesting (antennas) and transduction (reaction centers) in photochemical systems (PSI and PSII) and in a coupled electron and proton circuitry with active sources (pumps) and passive transport elements (chains and channels). The proper orientation and membrane organization of the photosynthetic machinery serves ( 1 ) the planar separation of two photochemical systems PSI and PSII, laterally connected by the cytochrome $b_{6} f$ complex that interacts with the plastoquinone (PQ) pool; it allows the uphill

Received 30 April 2017; accepted 1 November 2017, published as online-first 10 January 2018.

Phone: +31317 482147/+31318 430303, e-mail: wim@,vredenberg.nl

Abbreviations: CET - cyclic electron transport involving PSI; $\mathrm{CF}_{0} \cdot \mathrm{F}_{1}$ - subunits of chloroplasts ATPase; ECS - absorbance changes associated with the electrochromic band shift; $\mathrm{F}_{0}$ - fluorescence level of dark-adapted system with $100 \%$ open RCs; $\mathrm{F}_{\mathrm{m}}$ - fluorescence level of dark-adapted system with $100 \%$ closed RCs after fluorescence saturating pulse excitation; $g_{\mathrm{H}}{ }^{\text {thyl }}-$ the conductivity of the

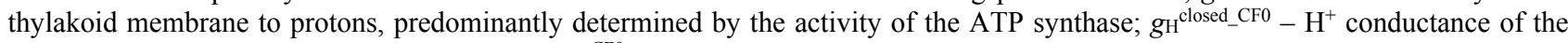
closed $\mathrm{CF}_{0}$ channel of the $\mathrm{CF}_{0} \cdot \mathrm{F}_{1} \cdot \mathrm{ATPase}$; $g_{\mathrm{H}}{ }^{\text {open_CF0 }}-\mathrm{H}^{+}$conductance of the open $\mathrm{CF}_{0}$ channel of the $\mathrm{CF}_{0} \cdot \mathrm{F}_{1} \cdot \mathrm{ATPase}$; LET - linear electron transport involving PSI and PSII; M - time range ( $\sim 30 \mathrm{~s})$ at which the final F-decline in the Kautsky induction curve starts; NPQ - nonphotochemical quenching; OJIPSMT - Kautsky fluorescence induction curve; $\mathrm{P}$ - time range ( $\sim 0.5-2 \mathrm{~s})$ in Kautsky induction curve where stimulation of variable chlorophyll fluorescence $\mathrm{F}$ by pmf and release of photochemical and electrochemical quenching is maximal; pmf - proton motive force; $\mathrm{RC}$ - reaction center of photosystem; $\mathrm{S}$ - time range $(\sim 15 \mathrm{~s})$ in Kautsky induction curve where the contribution of the slow component of F-decay has become minimal; SP - fluorescence saturating pulse with duration exceeding $3,000 \mathrm{~ms} ; \mathrm{sSP}$ - short fluorescence excitation light pulse with duration between 0.25 and $3,000 \mathrm{~ms} ; 3 \mathrm{k}(0.05 \mathrm{k})$ pulse - light pulse with intensity 3,000 (50) $\mu \mathrm{mol}$ (photon) $\mathrm{m}^{-2} \mathrm{~s}^{-1}$; $\mathrm{T}$ - time range (>2 min) in Kautsky induction curve where a (quasi) steady state in the light is reached; $\alpha$ - fraction of system with inactivated $\mathrm{CF}_{0} \cdot \mathrm{F}_{1} \cdot \mathrm{ATPase} ; \Delta \mu_{\mathrm{H}}$ - trans-membrane proton motive force; $\Phi_{\mathrm{H}^{+}}-$proton flux generated by light-driven proton pump.

Acknowledgements: I heartily thank Govindjee for his friendship, interest and support. I keep the best memories of occasions when we met during visits in the laboratories where we worked for most of the time of our careers: Urbana, Leiden, and Wageningen, and at several meetings since our first at the $1^{\text {st }}$ European Photosynthesis Congress in 1962 in Gif sur Yvette, France. I owe many thanks to my esteemed colleagues and former co-authors Alexander Bulychev (Botany Department, MSU, Russia) and Ondrej Prasil (Laboratory of Photosynthesis, Trebon, Czech Rep.) for the appreciated contributions and laboratory facilities that I have received. I thank Dr. Jeff Kay for the use of the OS5p + Modulated Chlorophyll Fluorometer (Opti Science, Hudson, USA) in which the routines and light-dark protocols for dedicated OJIPSMT measurements have been implemented.

(C) The Author(s). This article is published with open access at link.springer.com 
electron transfer from water in contact with the oxygenevolving complex (OEC) on the donor side of PSII to a reductant $\mathrm{NADP}(\mathrm{H})$ at the acceptor side of PSI; (2) exciton trapping, and subsequent trans-membrane charge separation in the reaction centers (RCs) of both photosystems that results in an electrogenic event associated with the generation of a trans-membrane electric potential $(\Delta \Psi)$ with associated electromotive force that acts as a driving force for the generation of electrochemical gradients of ions, in particular protons; (3) the anchoring and proper orientation of active proton pumps, such as the RCs, the cytochrome $b_{6} f$ complex, and the ATP(synth)ase (for recent surveys and schematic representations see Vredenberg 2011, Ebenhöh et al. 2014, Tikkanen and Aro 2014, Tikhonov 2015, Shikanai 2016). Many experimental and theoretical approaches from the basic life sciences have enabled time, structure, and function analyses of (parts of) the photosynthetic light and dark reactions down to the nano scale, or even lower. These have all thoroughly contributed to our present, but still incomplete, knowledge of this fascinating life process. The incompleteness amongst others comes from the failure so far to understand the details of the precision with which the photosynthetic architecture and network circuits reaches a high flexibility and responsiveness to short- and long-term changes in environmental factors, such as light, atmosphere, nutrition, etc. The availability of knowledge about properties and details of the orchestration and performers of the events that serve the proper rebalancing of the system to reach an adequate adaptation to the changes that happen is of prime importance for various areas of the experimental and applied plant and crop sciences.

Kinetic aspects of electron transport in PSI and PSII in chloroplasts and intact leaves have fruitfully been studied by monitoring kinetics of light-induced 810-nm absorbance changes $\left(\Delta \mathrm{A}_{810}\right)$, attributed to redox changes of P700 (Harbinson and Hedley 1993, Vredenberg and Bulychev 2010, Schreiber and Klughammer 2016), and of chlorophyll a (Chl) fluorescence induction responses, respectively (Stirbet et al. 1998, Vredenberg 2000, Papageorgiou and Govindjee 2004, Lazár and Schansker 2009, Vredenberg and Prášil 2009, Belyaeva et al. 2016). Recently light-dependent absorbance changes in the 510-535-nm wavelength region attributed to electrochromic band shifts of carotenoids (P515) have received

\section{Materials and methods}

Measurements were done with fresh leaves of a Spinacea sp. (spinach), bought in a local supermarket, Arum italicum (Aronskelk) or Saxifraga cuneifolia (Steenbreek), grown in the home garden, and with attached leaves of the ornamental plant Kalanchoë kept growing on the southoriented window-sill in the home office.

Fluorescence experiments were carried out using the modulated Chl fluorometer $O S 5 p^{+}$in its so called 'OJIP Vred' mode (Opti-Science Ltd., Hudson, USA) which and regained vivid attention. The monitoring of these signals has been considered to be promising for sensing trans- and inner-membrane electric fields and changes therein occurring in association with electron and proton transport that is powered by an electron motive (emf) and a proton motive force (pmf), respectively (Junge 1977, Witt 1979, Kramer and Crofts 1989, Vredenberg 1997, Johnson and Ruban 2014).

Here we report on recent results of light-driven variable Chl fluorescence $\left(F_{v}\right)$ measurements in intact (attached) leaves. Particular attention is given to light-on and -off kinetics of $F_{v}$ induced by low intensity light pulses (SP) with variable length in the $1-120$ s time range, or by a long train of short light pulses of 3 -s duration $\left(\mathrm{sSP}_{3 \mathrm{~s}}\right)$ and similar low intensity. The major part of the dark decay profiles after these pulses shows a (bi-phasic) pattern. This is composed of a fast and a slow exponential component, each with invariable relaxation time, different by a factor of $\sim 20$. The ratio between the size (amplitude) of the slow and fast decay component decreases with the magnitude of $F_{v}$ reached in the light at the end of the pulse. This characteristic pattern will be illustrated to be mechanistically different from that observed during the OJIP rise (Vredenberg 2015). The pattern is discussed to be in harmony with the hypothesis that the variable Chl fluorescence under low intensity conditions is due to stimulation by changes in the strength of local electric field(s) (Bulychev and Vredenberg 2001). These are discussed to be due to Coulombic interactions of protons that accumulate in association with the active proton fluxes $\left(\Phi_{\mathrm{H}^{+}}\right)$of the lumen-oriented light-driven proton pumps. The decay of the variable fluorescence should, in the context of the hypothesis, follow that of the pmf set by the driving proton flux when the latter is set at zero upon shutting of the light.

The similarity between the dark kinetics of $\mathrm{F}_{\mathrm{v}}$ and $\Delta \mu_{\mathrm{H}+}$ at different adaptation conditions will be discussed to give support for the hypothesis that the thylakoid-bound $\mathrm{CF}_{0} \cdot \mathrm{F}_{1} \cdot \mathrm{ATPase}$ has a regulatory and functional role in the electron and proton transport circuitry. This circuitry is responsive to (changes in) light intensity and plays a central role in the nonphotochemical quenching (NPQ) that is involved in the adaptation process (Kanazawa and Kramer 2002, Takizawa et al. 2008, Cardol et al. 2010).

enables application of programmable light-dark protocols for the application of actinic light pulses of variable duration and intensity (Vredenberg 2015). In the present paper, particular attention is given on monitoring light-on and -off kinetics of the variable fluorescence in low and high intensity red light pulses of $\sim 50$ and 3,000 $\mu \mathrm{mol}\left(\right.$ photon) $\mathrm{m}^{-2} \mathrm{~s}^{-1}$, respectively, and variable in length from $0.8 \mathrm{~s}$ to several tens of seconds. In short notation, the high and low intensity pulses are presented as $3 \mathrm{k}$ and $0.05 \mathrm{k}$ 
pulses, respectively. The time resolution of the variable fluorescence response during a light and dark period was variably chosen at values from $10 \mu \mathrm{s}$ to $1 \mathrm{~s}$, to guarantee and accommodate in particular a correct estimation of the rate constants for the individual components of the multiphasic responses during light and dark periods. Nomenclature of applied pulses was the following. Fluorescence saturating pulses with duration in the time range between $0.25-3,000 \mathrm{~ms}$ are denoted with sSP supplemented with a subscript referring to their exact duration. Those with duration above $3 \mathrm{~s}$ are denoted with SP and subscript. The term 'saturating' in the nomenclature of the low intensity $(0.05 \mathrm{k})$ pulses that have been used in the present communication should not lead to confusion. The term is meant to refer to the intensity range at which a (quasi-)steady-state level of the variable fluorescence $\mathrm{F}_{\mathrm{m}} / \mathrm{F}_{0}$ is reached. In all our cases, an $0.05 \mathrm{k}-\mathrm{sSP}$ [i.e. intensity of $50 \mu \mathrm{mol}$ (photon) $\mathrm{m}^{-2} \mathrm{~s}^{-1}$ ] causes, in confirmation with results in other plant species (Belyaeva et al. 2016), an estimated maximal variable fluorescence $\mathrm{F}_{\mathrm{m}} / \mathrm{F}_{0}$ in a range between 3.5-4.5. The corresponding $\mathrm{F}_{\mathrm{m}} / \mathrm{F}_{0}$ value after correction for the effect of the light-off rate, as will be discussed below, is in this saturation range. $F_{m} / F_{0}$ values with application of $3 \mathrm{k}-\mathrm{SPs}$ [intensity of 3,000 $\mu \mathrm{mol}$ (photon) $\mathrm{m}^{-2} \mathrm{~s}^{-1}$ ], are generally in the range between 5-6 (Papageorgiou and Govindjee 2004). The following light-dark protocol has routinely been used, unless stated otherwise, in the present experiments. It consists of a single train with three

\section{Results and interpretation}

The variable Chl fluorescence $\left(F_{v}\right)$ of intact algae and leaves emitted in a prolonged light pulse, also known as the Kautsky induction curve, shows a relatively fast OJIP rise followed by a gradual PSMT decrease extending into the minute time range (see chapters in Papageorgiou and Govindjee 2004). The $F_{v}$ rise from $F_{0}$ to a maximum $F_{m}$ is completed, depending on the intensity of the light pulse, in a time range of $0.5-5 \mathrm{~s}$. Fig. 1 shows, in this case for an attached Kalanchoë leaf and on a linear time scale, the $\mathrm{F}_{\mathrm{v}}$ $\left(=\mathrm{F} / \mathrm{F}_{0}-1\right)$ response in a high and low intensity light pulse of $3,000(3 \mathrm{k})$ and $50(0.05 \mathrm{k}) \mu \mathrm{mol}$ (photon) $\mathrm{m}^{-2} \mathrm{~s}^{-1}$, respectively. In the $0.05 \mathrm{k}$ intensity red pulse $\mathrm{F} / \mathrm{F}_{0}\left(=\mathrm{F}_{\mathrm{v}}+1\right)$ reaches the highest level at $\mathrm{P} \sim 4.1$ after about $3 \mathrm{~s}$ and subsequently decreases in the next $10-15 \mathrm{~s}$ to a level at $\mathrm{S} \sim 2.5$ after which it declines, via an intermediate level at $\mathrm{M}$ at about $30 \mathrm{~s}$ and slightly higher than $\mathrm{S}$, towards a level $\mathrm{T} \sim 1$ at 2-4 min (not shown). The induction curve in a 60 times higher (3k) intensity differs in its details from the one in the $0.05 \mathrm{k}$ pulse. The rise towards the maximum at $\mathrm{P} \sim 5.5$ occurs within $0.8 \mathrm{~s}$ and the gradual decline towards $\mathrm{T}$, with in this case $3>\mathrm{T}>1$ (not shown), occurs with much less pronounced intermediate levels $\mathrm{S}$ and $\mathrm{M}$. These two extreme patterns are globally independent of the plant species and agree well with those reported by others (Strasser et al. 1995, Papageorgiou et al. 2007, Vredenberg 2011, Lazár 2015). I will now focus on the kinetics of the successive light pulses. The dark period after each pulse in the train is $20 \mathrm{~s}$. The pulse train is started after a dark adaptation of the sample leaf for at least $10 \mathrm{~min}$. The $1^{\text {st }}$ and $3^{\text {rd }}$ pulse in the train are routinely of low $(0.05 \mathrm{k})$ intensity and with 3 -s duration $\left(\mathrm{sSP}_{3 \mathrm{~s}}\right)$. The $2^{\text {nd }}$ pulse in the train is of low $(0.05 \mathrm{k})$ intensity and 15 -s duration $\left(\mathrm{SP}_{15 \mathrm{~s}}\right)$. Application of the protocol is meant to alter the energetic state of a leaf from a prolonged dark- to a 15-s lightadapted one. It serves the possibility to compare the effect of this alteration on the light and dark kinetics of the variable fluorescence induced by a $0.05 \mathrm{k} \mathrm{sSP}_{3 \mathrm{~s}}$ given in the $1^{\text {st }}$ and $3^{\text {rd }}$ pulse of the train. The protocol, in other words, offers the possibility for detailed analysis of the effect of low intensity preillumination on the variable fluorescence of a dark-adapted leaf. A supplemental application of the protocol, by running it at a variable dark time between the $2^{\text {nd }}$ and the $3^{\text {rd }}$ pulse, allows the estimation of the dark recovery of the (pre-) illumination effect.

Experiments were done in situ at room temperature with, where appropriate, the movable fluorescencedetection probe of the fluorometer clipped on a leaf in its natural (attached) position on the plant.

The experimental traces in general represent the averages of five samples. Curve fitting of the experimental fluorescence responses was done with application of proper routines, provided by Excel software and dedicated equations for the distinct induction phases in the light and in the dark (Vredenberg 2011, 2015).

$\mathrm{F}_{\mathrm{v}}$ dark recovery at the beginning $(\mathrm{P})$ and end $(\mathrm{S})$ of the $\mathrm{F}_{\mathrm{v}}$ decline (see also Fig. 1) at about 3 and 15 s, respectively. This is done by applying the light-dark protocol, illustrated in Fig. 2. The $2^{\text {nd }}$ (blue colored) light pulse in a train of three is of 15 -s duration $\left(\mathrm{SP}_{15 \mathrm{~s}}\right)$ and low intensity $(0.05 \mathrm{k})$. The $1^{\text {st }}$ and $3^{\text {rd }}$ pulse (red colored) are identical and of 3 -s duration $\left(\mathrm{sSP}_{3 \mathrm{~s}}\right)$ and low intensity $(0.05 \mathrm{k})$. The three pulses are separated by dark periods of $20 \mathrm{~s}$. The $2^{\text {nd }}\left(\mathrm{SP}_{15 \mathrm{~s}}\right)$ pulse of the train acts as an inductor pulse which, owing to its (low) intensity and 15-s length, alters the variable fluorescence $F_{v}\left(=F / F_{0}-1\right)$ transiently from a lightadapted state $\mathrm{F} / \mathrm{F}_{0}=1$ at $\mathrm{O}$ towards a light-adapted state at $\mathrm{S}$. The $3^{\text {rd }}$ pulse, like the $1^{\text {st }}$ one, can be considered as the probing pulse of the light and dark kinetics of $\mathrm{F}_{\mathrm{v}} 20 \mathrm{~s}$ after the transfer of the leaf from a dark- to a light-adapted state. In this case, the $\mathrm{P}$ level in the $1^{\mathrm{st}} \mathrm{SSP}_{3 \mathrm{~s}}$ is at $\mathrm{P} \sim 4.2$; in the next following $\mathrm{SP}_{15 \mathrm{~s}} \mathrm{P} \sim 3.8$ and the $\mathrm{S}$ level is at $\mathrm{S} \sim 1.6$. In the $3^{\text {rd }}$ pulse, the $\mathrm{P}$ level is at $\mathrm{P}$ ' and nearly coinciding with the $\mathrm{S}$ level in the preceding inductor pulse. The half time of the P-S decline during $\mathrm{SP}_{15 \mathrm{~s}}$ is about $4 \mathrm{~s}$. The darkdecay after the pulses appears to be multiphasic with a pronounced difference between the pattern of the $1^{\text {st }}$ and $3^{\text {rd }}$ pulse fired after a 20-s dark adaptation of dark- (left hand panel) and light-adapted leaf, respectively. This becomes clearer after analysis of the decay patterns after illumination at a higher time resolution, as illustrated for a 
different leaf in detail in Fig. 3. The deconvolution shows for the pattern in the dark- and light-adapted state (left- and right-hand panel, respectively) a fit of the decay with the sum of three exponential functions $a_{i} \cdot \exp ^{-k i \cdot t}(i=1,2,3)$, in short notation labelled with the parameter set $\left[\mathrm{a}_{\mathrm{i}}, \mathrm{k}_{\mathrm{i}}\right]$, and $\mathrm{k}_{\mathrm{i}}$ in $\mathrm{s}^{-1}$ and $\Sigma a_{i}=1$. In the dark-adapted sample (left-hand

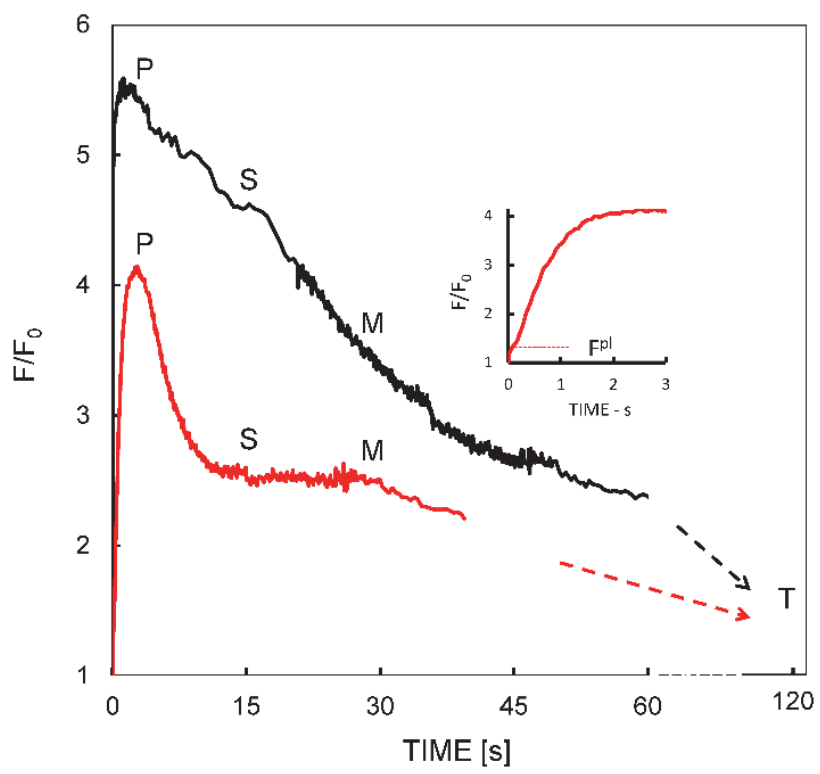

Fig. 1. The variable fluorescence O(JI)PSMT responses in an attached Kalanchoé leaf upon a 60-s light pulse ( $\left.\mathrm{SP}_{60 \mathrm{~s}}\right)$ of 3,000 and $50 \mu \mathrm{mol}\left(\right.$ photon) $\mathrm{m}^{-2} \mathrm{~s}^{-1}$ [black, (3k) and red, (0.05k) trace, respectively] on a linear timescale. The $3 \mathrm{k}$ - intensity induction curve differs in its details from the one in the $0.05 \mathrm{k}$ pulse. The $\mathrm{F} / \mathrm{F}_{0}\left(=\mathrm{F}_{\mathrm{v}}+1\right)$ rise from $\mathrm{F} / \mathrm{F}_{0}=1$ at the $\mathrm{O}$ level towards the maximum at $\mathrm{P} \sim 5.5$ occurs within $0.8 \mathrm{~s}$ and the subsequent gradual PSMT decline towards $\mathrm{T}$, with in this case $3>\mathrm{T}>1$ (not shown), occurs with weakly pronounced intermediate levels $\mathrm{S}$ and $\mathrm{M}$. In the $0.05 \mathrm{k}$ intensity pulse $\mathrm{F} / \mathrm{F}_{0}\left(=\mathrm{F}_{\mathrm{v}}+1\right)$ reaches the highest level at $\mathrm{P} \sim 4.1$ after about $3 \mathrm{~s}$ and subsequently decreases in the next $10-15 \mathrm{~s}$ to a level at $\mathrm{S} \sim 2.5$ after which via an intermediate level at $\mathrm{M}$ at about $30 \mathrm{~s}$, slightly higher than $\mathrm{S}$, declines towards a level $\mathrm{T} \sim 1$ at $2-4 \mathrm{~min}$ (not shown). The relatively fast $\mathrm{P}-\mathrm{S}$ decline in the variable fluorescence response during the first $15 \mathrm{~s}$ of illumination with a low intensity $(0.05 \mathrm{k})$ light pulse $\left(\mathrm{SP}_{15 \mathrm{~s}}\right)$ will receive special attention in the next figures. The inset shows, on an extended time scale, the initial response with the rapid rise within $100 \mathrm{~ms}$ to the level $\mathrm{F}^{\mathrm{pl}} \sim 1.25$, attributed to the photochemical reduction of the $\mathrm{Q}_{\mathrm{B}}$-nonreducing RCs.

panel), the $\mathrm{F}_{\mathrm{v}}$-decay after $\mathrm{SSP}_{3 \mathrm{~s}}$ starts at level $\mathrm{P}(\mathrm{P} \sim 3.0)$ and runs with a fast component $\left[\mathrm{a}_{1}, \mathrm{k}_{1}\right] \sim[0.3,28]$ into a slow one $\left[\mathrm{a}_{2}, \mathrm{k}_{2}\right] \sim[0.3,0.5]$ and terminates via an ultraslow component $[\mathrm{a} 3, \mathrm{k} 3] \sim[0.4,0.1]$ at $\mathrm{F}_{0} \sim 1$ (not shown). In the light-adapted state (right-hand panel) the respective fit parameters of the $\mathrm{F}_{\mathrm{v}}$ decay in the dark, starting at level $\mathrm{P}^{\prime}\left(\mathrm{P}^{\prime} \sim 1.9\right)$, are $[0.5,28],[0.1,0.6]$, and $[0.4,0.1]$. The typical fluorescence response pattern of Fig. 3 is reproducibly found in leaves of various plants species (Spinacia sp., Arum italicum, Saxifraga cuneifolia, etc.) under similar light and dark conditions.

It is obvious from the data in Figs. 2 and 3 that the decline in the $\mathrm{F}_{\mathrm{v}}$ amplitude during light adaptation from $\mathrm{P}$ towards $\mathrm{S}$ (middle panel in Fig. 1), is accompanied by a significant change in the amplitude ratio $a_{2} /\left(a_{1}+a_{2}\right)$ of the slow and fast components of the decay when the light is shut-off at these approximate levels (Fig. 3). The contribution of the ultra-slow decay component $\left(\mathrm{a}_{3}, \mathrm{k}_{3}\right)$ is found to change much less with light adaptation (Fig. 3). A second important observation from the data illustrated in Fig. 3 is that the rate constants of the fast $\left(\mathrm{k}_{1}\right)$ and slow $\left(\mathrm{k}_{2}\right)$ component of the $\mathrm{F}_{\mathrm{v}}$ decay are hardly, if at all, altered after a pronounced decrease in variable fluorescence during the $\sim 12 \mathrm{~s}$ P-S decline in a low light-intensity pulse. These two facts together exclude a fluorescence-quenching mechanism, like those that has been illustrated to be involved in the photochemical phase of the OJIP induction curve (Vredenberg 2015). There, a change in the extent of quenching, i.e. in $\mathrm{F}_{\mathrm{v}}$, has been shown to be accompanied by a change in rate constants of photochemical redox conversions of the quencher $\mathrm{Q}_{\mathrm{A}}$ in the light and the dark.

Fig. 4 gives the superposition of four successive responses of variable fluorescence of the same Saxifraga leaf as of Fig. 3 upon running the light-dark protocol at a variable length of the dark period between the $2^{\text {nd }}$ and $3^{\text {rd }}$ pulse. It illustrates the recovery of the $\mathrm{SP}_{15 \mathrm{~s}}$-induced $\mathrm{F}_{\mathrm{v}}$ alteration in dependence of the dark time elapsed since its induction. The reversal in the dark of the pulse-induced- $F_{v}$ decrease appears to occur with a half time of approx. $1 \mathrm{~min}$. The curves at progressing dark time show that the recovery of the $\mathrm{F}_{\mathrm{v}}$ amplitude in an $\mathrm{sSP}_{3 \mathrm{~s}}$ pulse is accompanied by an increase in the extent of the slow decay phase and in the ratio between that of slow and fast phase. Thus, the data from Figs. 2-4 somehow indicate that light adaptation of a dark-adapted leaf during a 15-s illumination with low intensity light alters the dark-reversible constitution of a quenching system with at least two interconvertible actors. This alteration, with a lifetime of several tens of seconds, results in a lower variable fluorescence and is reflected by a change in the ratio between the sizes of two complementary quenching actors characterized by a large difference in their lightindependent recovery rate in the dark after light activation.

Fig. 5 shows, for a dark-adapted $(>2 \mathrm{~h})$ spinach leaf, the $F_{v}$ response upon application of a modified light-dark protocol, in which the low intensity $(0.05 \mathrm{k}) 1^{\text {st }}$ and $3^{\text {rd }}$ pulses (red) are replaced with a high intensity one (3k) with 0.8 -s duration $\left(\mathrm{sSP}_{0.8 \mathrm{~s}}\right)$ and a dark time between $2^{\text {nd }}$ and $3^{\text {rd }}$ pulse shortened to $10 \mathrm{~s}$. The $\mathrm{F}_{\mathrm{v}}$ response induced by the $2^{\text {nd }} 0.05 \mathrm{k}$-pulse (blue), in this case of 30 -s duration $\left(\mathrm{sP}_{30 \mathrm{~s}}\right)$, shows similarities with the one monitored in Fig. 2 for a Kalanchoë leaf with all pulses of low $(0.05 \mathrm{k})$ intensity. The $\mathrm{P}-\mathrm{S}$ decline is from $\mathrm{P} \sim 3.7$ to $\mathrm{S} \sim 1.8$, and the response ( $3^{\text {rd }}$ pulse) after light activation by $\mathrm{SP}_{30 \mathrm{~s}}$ shows a pattern different from that in the dark-adapted leaf $\left(1^{\text {st }}\right.$ pulse $)$. 

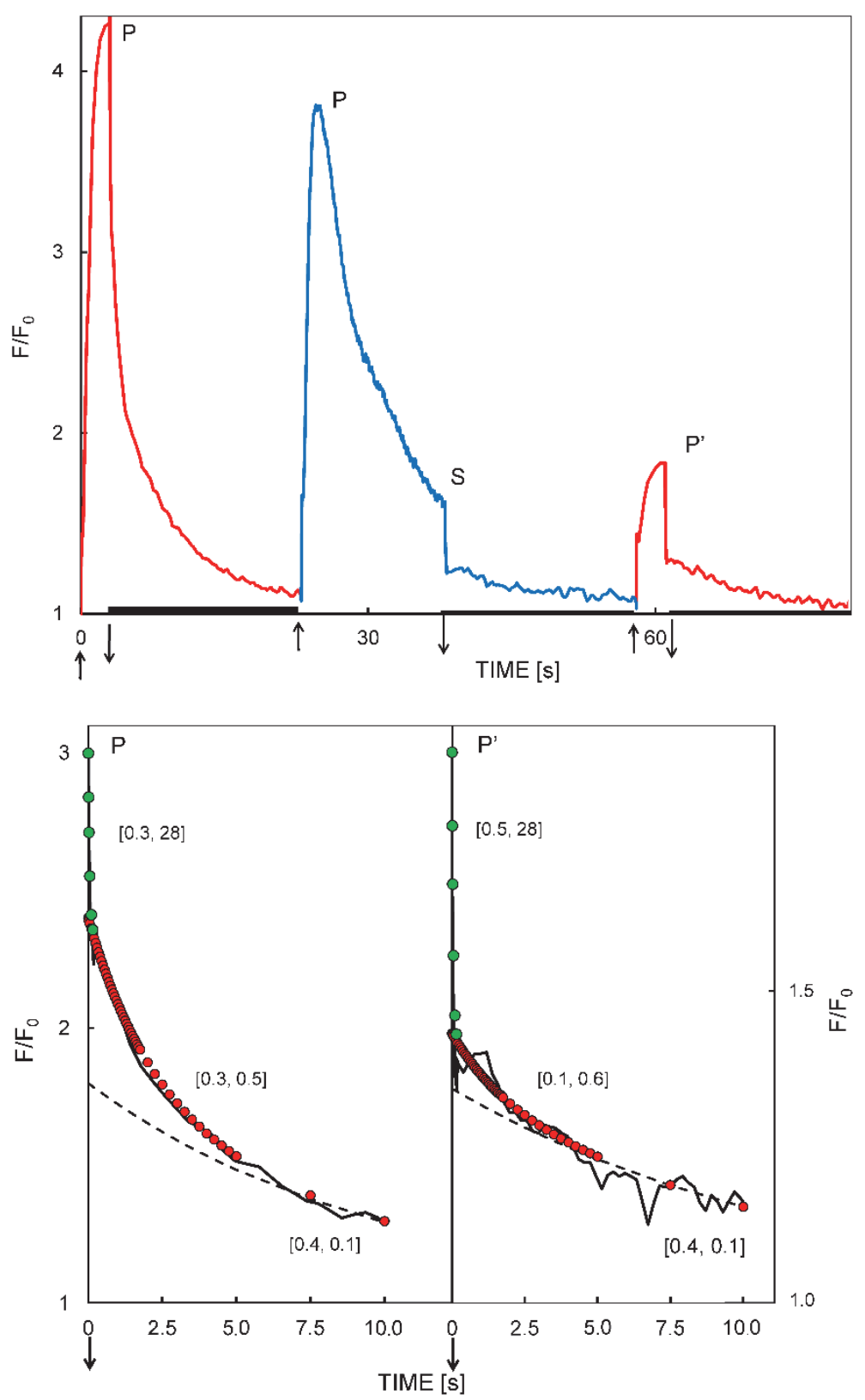

Fig. 2. The $F / F_{0}\left(=F_{v}+1\right)$ response of a dark-adapted Saxifraga cuneifolia leaf subjected to a light-dark protocol that consists of a single train with three successive light pulses. The dark period after each pulse in the train is $20 \mathrm{~s}$. The $1^{\text {st }}$ and $3^{\text {rd }}$ pulse are identical and routinely of low $(0.05 \mathrm{k})$ intensity and with $3 \mathrm{~s}$ duration $\left(\mathrm{sSP}_{3 \mathrm{~s}}\right)$. The $2^{\text {nd }}$ pulse is of low $(0.05 \mathrm{k})$ intensity and 15 -s duration $\left(\mathrm{SP}_{15 \mathrm{~s}}\right)$. Onset and cessation of the pulses are indicated with upward and downward pointing arrows, respectively. The dark periods are illustrated with horizontal black bars. The figure illustrates that (1) the profile of the $\mathrm{F}_{\mathrm{v}}$ in the dark after cessation of the pulse at $\mathrm{P}$ (S and P') is substantially altered after a 15 -s pre-illumination with low intensity actinic light, and (2) the darkrecovery of this alteration is takes a longer time than that of its inductor $\left(\mathrm{P}>>\mathrm{P}^{\prime} \sim \mathrm{S}\right)$.

Fig. 3. Dark responses (black curves) of the variable fluorescence response $\mathrm{F}_{(\mathrm{t})} / \mathrm{F}_{0}$ after a 3 -s $0.05 \mathrm{k}$ pulse $\left(\mathrm{sSP}_{3 \mathrm{~s}}\right.$ ), i.e. of $50 \mu \mathrm{mol}$ (photon) $\mathrm{m}^{-2} \mathrm{~s}^{-1}$ intensity, measured in a $>2$-h dark-adapted Saxifraga cuneifolia leaf before (left-hand trace) and $20 \mathrm{~s}$ after (righthand curve) a pre-illumination with the same pulse $\left(\mathrm{SP}_{15 \mathrm{~s}}\right)$ of $15-\mathrm{s}$ duration. The curves have been deconvoluted with three exponential functions with amplitude and rate constant $\mathrm{a}_{\mathrm{i}}$ and $\mathrm{k}_{\mathrm{i}}$, respectively, and denoted with $\left[a_{1}, k_{i}\right]$ with $i=1,2,3$. The graph of the ultra-slow (slowest) component is illustrated by the black dashed bottom line [a3.k3], the red- and green circled symbols are superimposed on that of the slower one(s), those of the slow and fast components $\left[\mathrm{a}_{2}, \mathrm{k}_{2}\right]$ and $\left[\mathrm{a}_{2}, \mathrm{k}_{2}\right]$, respectively. The figure shows that the alteration in the amplitude $\left(\mathrm{a}_{1}+\mathrm{a}_{2}+\mathrm{a}_{3}\right)$ of the response associated with pre-illumination is mainly due to that of $a_{2}$. The rate constants of the three components are found not to alter significantly, and are estimated to be in the range $25-35,0.5-1.5$, and $<0.1 \mathrm{~s}^{-1}$, respectively.
Fig. 6 gives an illustration for the same experiment as in Fig. 5, the time-resolved kinetics of the $F_{v}$ dark decay in the (linear) time range of $5 \mathrm{~s}$ before and after light activation by the $2^{\text {nd }}$ pulse of the protocol. Similarly as in the Kalanchoe leaf (Fig. 3), the decay is multiphasic with, in addition to a relatively small and invariable ultra-slow component, two complemental components with, for this spinach leaf, a fast and slow recovery rate of $\sim(20 \mathrm{~s})^{-1}$ and $\sim(0.4 \mathrm{~s})^{-1}$, respectively. The rates do not alter significantly after the pre-illumination, whereas the size of the relative fraction of the slow fraction contributing to the decay decreased from $\sim 48 \%$ in the dark-adapted leaf to $\sim 32 \%$ in the same leaf after 15 -s pre-illumination with low intensity light. Thus, like suggested before, the constitution of a quenching-competent actor system is altered by a short low intensity pulse $\left(\mathrm{sP}_{30 \mathrm{~s}}\right)$ and sensed by the dissipative processes initiated at manifold higher intensities. It is instructive to point to the fact that the decay patterns of $F_{v}$ after high intensity $(3 \mathrm{k}) \mathrm{sSP}_{0.8 \mathrm{~s}}$ are qualitatively similar to those after low $(0.05 \mathrm{k}) \mathrm{SSP}_{3 \mathrm{~s}}$ (Fig. 3), despite the fact of a high(er) contribution of $F_{v}$ changes associated with photochemical quenching in the high intensity pulse (Fig. 1). This indicates, in agreement with published data (Vredenberg 2015), a faster decay of $F_{v}$ changes in the dark after photochemical induction as compared to those associated with nonphotochemical origin.

Further details of the effect of light activation on the quenching acts are observed after plotting the $\mathrm{O}-\mathrm{P}$ rise upon the 0.8 -s high intensity pulses $\left(\mathrm{sSP}_{0.8 \mathrm{~s}}\right)$ illustrated in Fig. 5 on a logarithmic time scale. This is illustrated in 

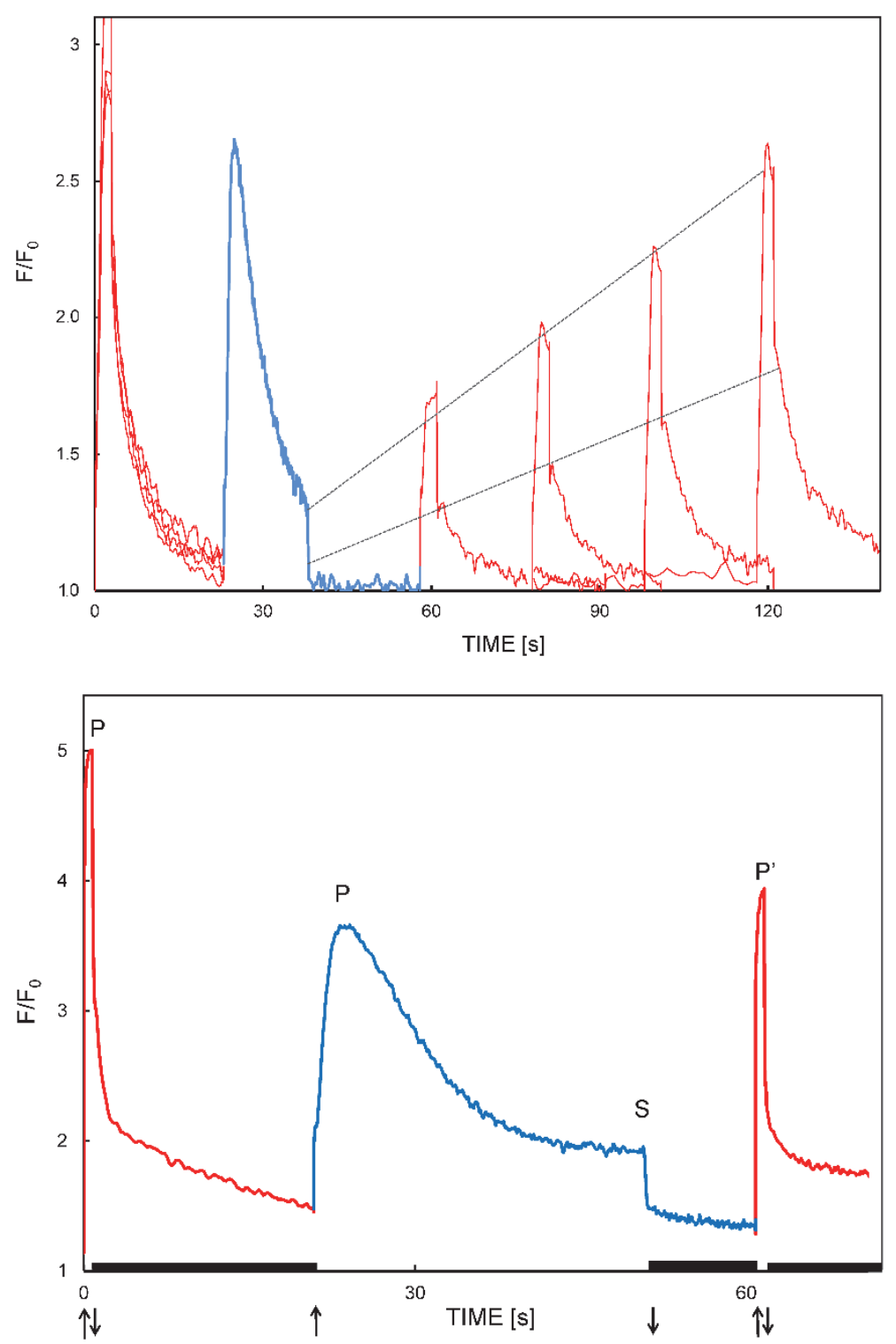

Fig. 4. Superposition of the successive responses of the variable fluorescence $F_{v}$ of a Saxifraga leaf, same as used in Fig. 3, upon running the light-dark protocol of Fig. 2, except for the length of the dark period between the $2^{\text {nd }}$ (pump, blue) and $3^{\text {rd }}$ (probe, red) pulse which was set variable between 20 and $80 \mathrm{~s}$ with an increment of $20 \mathrm{~s}$ for each individual protocol within the succession procedure. The repetition rate of the protocol application was $(8 \mathrm{~min})^{-1}$. Note the increase in the ratio between the slow and rapid component of the decay with the progression of the recovery of the probe signal. The blue pulse signal is the average of the four individual responses.

Fig. 5. Application of a light-dark protocol, similar as used in Fig. 2, for monitoring the $F / F_{0}\left(=F_{v}+1\right)$ response of a $>2$-h dark-adapted Spinach leaf. The protocol consists of the central low intensity $(0.05 \mathrm{k})$ light pulse (L) of 15-s duration (blue), identical to the one used in Fig. 2, and a preceding and next following high intensity (5k) pulse (red curve) of 0.8-s duration $\left(\mathrm{sSP}_{0.8 \mathrm{~s}}\right)$. The (red) pulses are separated from the central one by, in this case, dark periods of 20 and $10 \mathrm{~s}$, respectively. Onset and cessation of the light pulses are indicated with upward and downward pointing arrows, respectively. The dark periods are illustrated with horizontal black bars. The figure illustrates that (1) the profile of the $\mathrm{F}_{\mathrm{v}}$ decay in the dark from its maximal $P$ level after a high intensity pulse is substantially altered after a 15-s preillumination with low intensity actinic light, and (2) a decrease of maximal $F_{v}$ amplitude indicated by the P' level shortly after low intensity pre-illumination.
Fig. 7 for an Arum italicum leaf. The fluorescence induction curve in high intensity $3 \mathrm{k}$-light shows for the dark-adapted leaf the well know O-P rise in about $0.6 \mathrm{~s}$, with for this leaf $\mathrm{P} \sim 4.7$, and inflections at levels $\mathrm{J} \sim 2.9$ and I $\sim 4$ at about 3 and $35 \mathrm{~ms}$, respectively. The fluorescence induction measured $10 \mathrm{~s}$ after short light activation by a low intensity $(0.05 \mathrm{k}) \mathrm{SP}_{30 \mathrm{~s}}$ shows, except for the an unaltered $\mathrm{O}-\mathrm{J}$ rise, a complete and nearly full suppression of the $\mathrm{J}-\mathrm{I}$ and $\mathrm{I}-\mathrm{P}$ rise, respectively, with levels at $\mathrm{J}$ ' $=$ $\mathrm{J} \sim 2.9, \mathrm{I} '=\mathrm{J} \sim 2.9$, and $\mathrm{P}^{\prime} \sim 3.2$. Fig. 5 and 7 clearly show, in full agreement with what has been found before in the alga Scenedesmus, that the $\mathrm{SP}_{30 \text { s }}$-fluorescence decline

\section{Discussion}

The present paper focuses on light-dark kinetics and amplitude of the variable $\mathrm{Chl}$ fluorescence $\mathrm{F}_{\mathrm{v}}$ during the declining phase of the well-known Kautsky induction observed in the P-S phase of the PSMT induction (Fig. 5) does not affect the rate and extent of the (photochemical) quenching during the photochemical O-I phase at the onset of illumination (Vredenberg et al. 2012). The $\mathrm{SP}_{30 \mathrm{~s}}$ induced suppression of the thermal J-I-P phase (Fig. 7) shows strong similarities with that reported to occur in chloroplasts after addition of protonophoric agents like CCCP ( Vredenberg et al. 2007). This would indicate that the JIP rise and the $\mathrm{P}-\mathrm{S}$ decline of the variable $\mathrm{Chl}$ fluorescence in the light bear a relation with (changes in) the proton conductance of the thylakoid membrane.

curve in the light in intact leaves. Application of pulses of variable length in a range of subseconds to several minutes serves a covering of the constituting $\mathrm{O}(\mathrm{J}) \mathrm{IP}$ and PSMT 


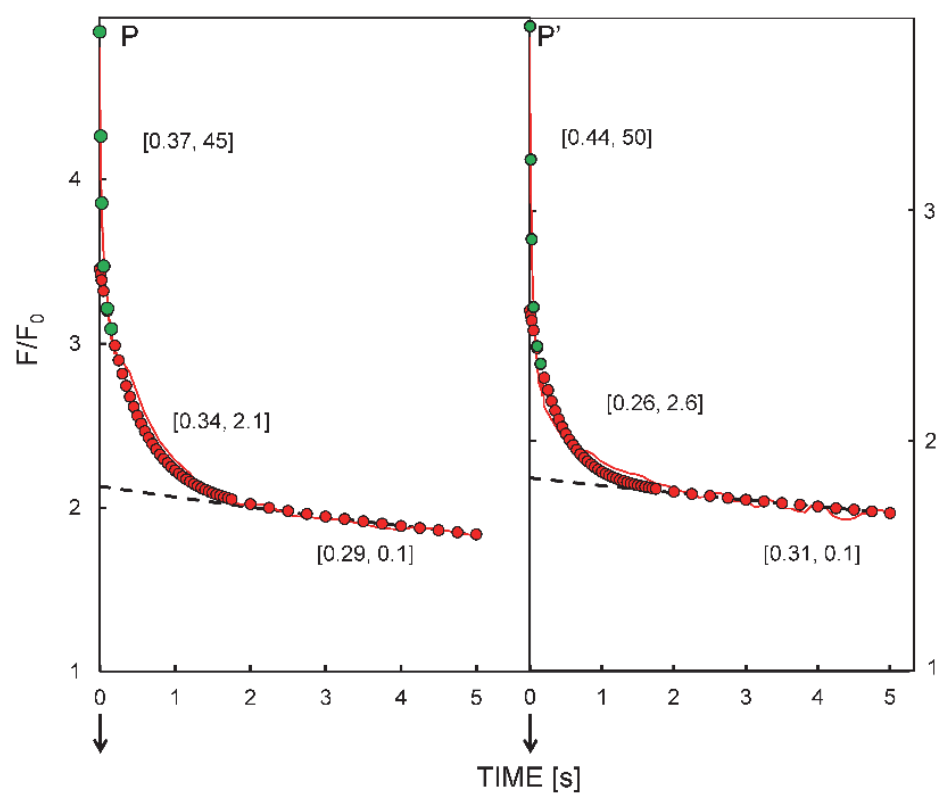

Fig. 6. Dark responses (thin red lines) of the variable $\stackrel{\circ}{\circ}^{\circ} \quad$ fluorescence response $\mathrm{F}_{(\mathrm{t})} / \mathrm{F}_{0}$ after a 0.8 -s $3 \mathrm{k}$ pulse $\left(\mathrm{sSP}_{0.8 \mathrm{~s}}\right)$, i.e. intensity of $3,000 \mu \mathrm{mol}$ (photon) $\mathrm{m}^{-2} \mathrm{~s}^{-1}$, measured in a $>2$-h dark-adapted Spinach leaf (same experiment of Fig. 5) $20 \mathrm{~s}$ before (left-hand trace) and $10 \mathrm{~s}$ after a 0.05 pre-llumination pulse $\left(\mathrm{SP}_{15 \mathrm{~s}}\right)$ of 15-s duration (right-hand curve). Deconvolution with three exponential functions and meaning of symbols are as in Fig. 4. The figure shows that the alteration in the amplitude of the high intensity-induced $F_{v}$ response associated with low intensity preillumination is for a major part due to an attenuation of the slow decay component (a 2 ). Parameter values $\left(\mathrm{k}_{\mathrm{i}}, \mathrm{i}=1-3\right)$ are in the range $45-50,2-2.5$, and $<$ $0.1 \mathrm{~s}^{-1}$, respectively.

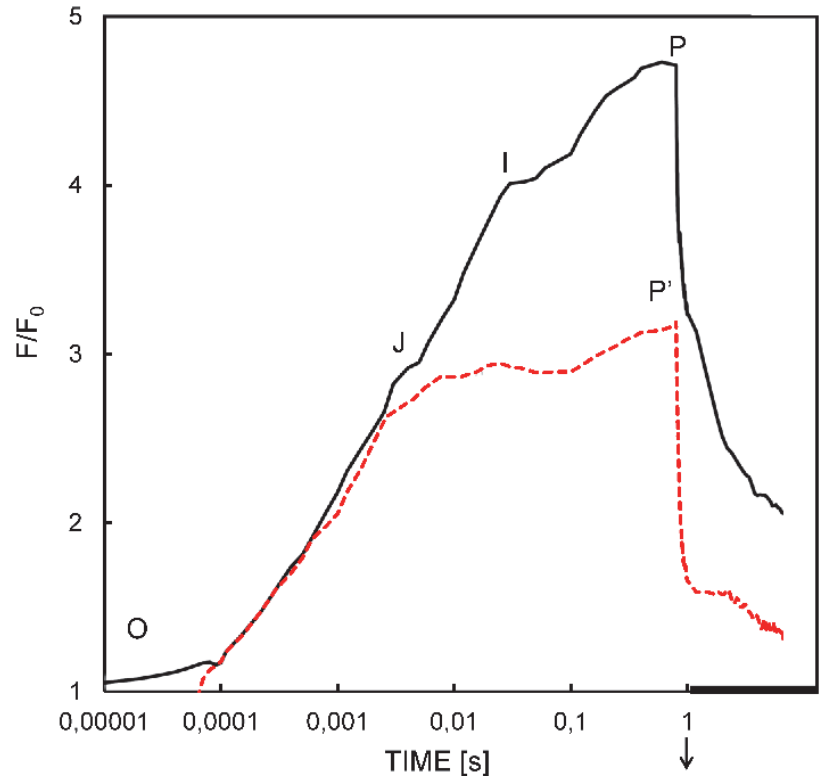

Fig. 7. Logarithmic time plot, measured in an Arum italicum leaf, of the OJIP fluorescence induction response during and after a 0.8 -s high intensity ( $3 \mathrm{k}$ ) pulse, when monitored $20 \mathrm{~s}$ before (blueshadowed black curve) and $10 \mathrm{~s}$ after a 30 -s low intensity $(0.05 \mathrm{k})$ pulse (dashed red curve). The figure shows that short preillumination with low intensity actinic light has little, if any, effect on the initial rate and extent (amplitude) of photochemical O-J component of the variable fluorescence that comes into expression in the OJIP induction curve. The major effect of preillumination is expressed in a strong, if not complete inhibition of the thermal J-I and I-P phases.

phase of the variable fluorescence response, respectively. Experiments with pulses in the $0.01-\mathrm{ms}$ to 1 -s time range of the rising OJIP part of the $F_{v}$ induction have been given ample attention and discussion in a previous paper (Vredenberg 2015). These were shown to contribute to the distinction, identification, and characterization of a photochemical OJ and a thermal JIP phase. They were discussed to point to the necessity for an evaluation of conflicting models that have been derived from results obtained with application of different fluorometric methods and reasoning. Here, the main focus is on the analysis of the $\mathrm{F}_{\mathrm{v}}$ kinetics during and after pulses with duration in the 1-100-s time range covering the declining PSMT part of the induction. These, as we will see, are conceptually different from those associated with $\mathrm{F}_{\mathrm{v}}$ changes that are observed during the photochemical $\mathrm{O}-\mathrm{J}$ phase and the subsequent $\mathrm{J}-\mathrm{I}$ part of the thermal phase.

To minimize interferences with fluorescence changes associated with activation during the photochemical $(\mathrm{O}-\mathrm{J})$ and (part of) the thermal phase (J-I), the fluorescence responses are measured with low-intensity, usually less than $100 \mu \mathrm{mol}$ (photon) $\mathrm{m}^{-2} \mathrm{~s}^{-1}$, actinic pulses. At these intensities changes attributed to photochemical and (part of) thermal activation, are found to be negligibly small, except for the one associated with the photochemical reduction of $\mathrm{Q}_{\mathrm{B}}$-nonreducing RCs (Vredenberg 2011). This reduction shows up (Chylla and Whitmarsh 1989) as the fast initial $F_{(t)}$ rise towards the so called $F^{p l}$ level (Fig. 1, insert). In agreement with other reports (Strasser et al. 1995, Vredenberg 2011), the I-P part of the thermal phase in low intensity light pulses is stimulated as compared to that at higher intensities. In our hands, using low intensity $(0.05 \mathrm{k})$ light pulses [intensity $=50 \mu \mathrm{mol}$ (photon) $\mathrm{m}^{-2} \mathrm{~s}^{-1}$, the I-P rise in leaves of a variety of plant species reaches a maximal level at $\mathrm{P}$ with $\mathrm{F}_{\mathrm{v}}\left(=\mathrm{F} / \mathrm{F}_{0}-1\right)$ in the range between 2.7 and 3.2, which is $\sim 30 \%$ less than that reached in a 60 -fold higher intensity. The choice for using low intensity light pulses is paid-off by the appearance of a prominent $\mathrm{P}-\mathrm{S}$ decline of the variable fluorescence during the 3-15-s time period in the weak light. This prominence has been reported by others (Strasser et al. 
1995, Lazár 2015, Stirbet and Govindjee 2016). It is likely due to the attenuation of effects associated with the suppression of photochemical and thermal quenching at the low intensity used.

Now one arrives at the question about the mechanism of the processes that is (are) responsible for the relative fast decline in variable fluorescence in weak light during the $\mathrm{P}-\mathrm{S}$ part of the PSMT phase. We have found and figures show that in dark-adapted leaves the decrease of $F_{v}$ from level $\mathrm{P}$ to $\mathrm{S}$ in low light is between 50 and $70 \%$ of $\mathrm{F}_{\mathrm{v}}$ at $\mathrm{P}$. As the size of the $F_{v}$ signal is the resultant of lightpromoting and of counteracting dark-recovery processes, it is required that the kinetics of the changes during and after cessation of an illumination pulse become known. For this purpose a flexible light-dark protocol consisting of a train of three successive low intensity light pulses was used (Fig. 2). Application of this protocol to a dark-adapted leaf provides a useful means to scan and compare the dark kinetics of $F_{v}$ at its maximum level in a dark- and lightadapted leaf, respectively. It should be noted that the lightadapted state induced by the $2^{\text {nd }}$ pulse ( $\mathrm{S}$ level in Fig. 2 ) is measured after a 20 -s dark period at the low(er) $\mathrm{P}^{\prime}$ level in the $3^{\text {rd }}$ pulse, i.e. $20 \mathrm{~s}$ after a small dark recovery of this $\mathrm{S}$ state $\left(\mathrm{P}>>\mathrm{P}^{\prime}>\mathrm{S}\right)$. It is obvious that the kinetic profile of the fluorescence dark reversion from the maximum of an SSPinduced $F_{v}$ is substantially different in a dark- and lightadapted leaf. This is also true for the $F_{v}$ curves measured in the $3^{\text {rd }}$ pulse at increasing separation times from the central $\mathrm{SP}_{15 \mathrm{~s}}$ in the reverse direction (Fig. 4). The size of a slow decay component running into the 20 -s range is strongly reduced after light adaption with a recovering reversal upon dark adaptation with a halftime of the order of $1 \mathrm{~min}$ (Fig. 4). A further precision of apparent alterations in the dark-decay pattern of the variable fluorescence has been derived from the kinetic analyses at high time resolutions (Figs. 3,6). These show, except for an altered $\mathrm{F}_{\mathrm{v}}$ amplitude after light adaptation, a change in the relative size of three constituting fast, slow and ultra-slow decay components with invariable rates (in $\mathrm{s}^{-1}$ ) of $\sim 30$, $\sim 1.5$, and $<0.1$, respectively. The data illustrate that the lower $\mathrm{F}_{\mathrm{v}}$ maximum after low intensity light adaptation of dark-adapted leaves is associated with (1) an increase in the relative contribution of the fast $\left(\mathrm{k}_{1} \sim 30 \mathrm{~s}^{-1}\right)$ decay component and, conversely (2) a complementing decrease in the contribution of the slow $\left(\mathrm{k}_{2} \sim 1 \mathrm{~s}^{-1}\right)$ phase, and (3) a relatively small and invariable contribution of an ultraslow $\left(\mathrm{k}_{3}<0.1 \mathrm{~s}^{-1}\right)$ part.

The decrease in $\mathrm{F}_{\mathrm{v}}$ associated with light adaptation, combined with an invariability of the rate constants and a decrease in the amplitude ratio of the major fast and slow components of the $F_{v}$ decay in the dark cannot be explained and modelled in terms of reaction kinetics of an electron transport-driven conversion of a single quencher. These were, for instance, shown to be involved in the initial $\mathrm{O}-\mathrm{J}$ phase of the fluorescence induction phase (Vredenberg 2015). There, an increase in the amplitude of the variable fluorescence at the $\mathrm{J}$ level has been shown to be inversely related to the recovery (reoxidation) rate of the reduced form of the photochemical quencher $\mathrm{Q}_{\mathrm{A}}$ of PSII (Vredenberg and Prášil 2009, and references therein). Here, the data analysis shows that the decrease of $F_{v}$ during the $\mathrm{P}-\mathrm{S}$ phase of the light-driven induction is accompanied by a complementary change of the amplitudes of the fast and 25- to 40-fold slower component of the $\mathrm{F}_{\mathrm{v}}$ decay in the dark without, or only small, changes in the rate constants. This suggests that the amplitudes of these two major $F_{v}$ decay components are related to the fractional size of two different quenching-promoting entities that are involved. This would indicate that the $\mathrm{F}_{\mathrm{v}}$ decrease of the $\mathrm{P}-\mathrm{S}$ phase is accompanied by a gradual decrease in the concentration of an entity or substance with an invariable recovery rate in the dark and opposed by an increase in that of an entity with a manifold higher invariable recovery rate. It is then tempting to presume that these quenching entities or actors are interconvertible in light and darkness. To my knowledge, there is no evidence available so far for the existence of photochemical quenchers with these properties. This then leads to the conclusion that light adaptation (preillumination) of a dark-adapted leaf with weak actinic light causes a dark-reversible quenching of the variable fluorescence of which the decay in the dark is characterized by two major interconvertible components of complementary size and invariable rates constants that differ by a factor of $25-40$.

The declining PSMT phase of the variable fluorescence in a Kautsky curve is thought and has been illustrated to be caused by nonphotochemical quenching NPQ (Papageorgiou and Govindjee 2014, Lazár 2015). NPQ is known to be partitioned in three main components $\mathrm{q}_{\mathrm{E}}, \mathrm{q}_{\mathrm{T}}$, and $\mathrm{q}_{\mathrm{I}}$ associated with energy-dependent processes, state transitions, and photoinhibition, respectively. These have been shown to occur in progressive time domains ranging from seconds to hours. The notion that the fluorescence changes that we deal with here occur in light and dark periods of tens of seconds, indicates that they are associated with the major and quickly reversible $\mathrm{q}_{\mathrm{E}}$ component of NPQ. $\mathrm{q}_{\mathrm{E}}$ is attributed to the light-generated trans-thylakoid $\mathrm{pH}$ gradient which causes in the presence of $\mathrm{PbS}$ and zeaxanthin the promotion of energy-dissipative reactions in the light-absorbing antenna complex of PSII, and consequently a lowering of the Chl fluorescence yield. (Horton et al. 1996, Niyogi et al. 2005, Pascal et al. 2005). The formation of a $\Delta \mathrm{pH}$ is a result of the operation of membrane-localized proton pumps that serves the generation of a trans-thylakoid proton motive force (pmf). The pmf (Cruz et al. 2001) is, characteristic for a current generating device, linear related to the pump-generated proton flux $\Phi_{\mathrm{H}}^{+}$, and inversely dependent on the membrane proton conductance

$$
g_{\mathrm{H}}^{\text {thyl }}=\alpha \cdot g_{\mathrm{H}}^{\text {closed_CF0 }}+(1-\alpha) \cdot g_{\mathrm{H}}^{\text {open_CF0 }},
$$

in which $g_{\mathrm{H}}^{\text {closed_CF0 }}$ and $g_{\mathrm{H}}^{\text {open_CF0 }}\left(\gg g_{\mathrm{H}}^{\text {closed_CF0 }}\right)$ are the $\mathrm{H}^{+}$conductance of the closed and open $\mathrm{CF}_{0}$ channels of the 
$\mathrm{CF}_{0} \cdot \mathrm{F}_{1} \cdot \mathrm{ATPase}$, respectively; $\alpha$ is the fraction of the system with closed $\mathrm{CF}_{0}$ channels, i.e. with $g_{\mathrm{H}}^{\text {thyl }}=$ $g_{\mathrm{H}}^{\text {closed_CF0 }}$. It can easily be derived that for a proton-pump circuitry, at constant $\Phi_{\mathrm{H}}{ }^{+}$, the exponential pmf decay upon cessation of the pump activity by setting $\Phi_{\mathrm{H}}{ }^{+}=0$ occurs with two components of which the ratio between the low $\left(\mathrm{k}_{\mathrm{c}}\right)$ and high rate constant $\left(\mathrm{k}_{\mathrm{o}}\right)$ is equal to $g_{\mathrm{H}}^{\text {closed_CF0 }} / g_{\mathrm{H}}^{\text {open_CF0 }}$.

Our data on the characteristics of the dark kinetics of $\mathrm{F}_{\mathrm{v}}$ after a low intensity $(0.05 \mathrm{k})$ pulse are in harmony with the hypothesis that a major part of the variable fluorescence $F_{v}$ in these pulses is caused by changes in photoelectric events in the photosynthetic membrane and associated with active trans-membrane proton pumping into the chloroplast lumen. The effect of the interaction of an electric field, in this case associated with the pmf, with the energy levels in the $\mathrm{RC}$ on the Chl fluorescence has been amply discussed (van Grondelle 1985, Bulychev and Vredenberg 2001, Vredenberg and Prášil 2009). Our fluorescence decay kinetics (Figs. 3,5) show remarkable resemblance with those, as discussed above, of the lightoff kinetics of the trans-thylakoid proton motive force. They add as such supporting evidence to the hypothesis on the association of these fluorescence changes with the proton conductance (changes) of the $\mathrm{CF}_{0} \cdot \mathrm{F}_{1} \cdot \mathrm{ATPase}$ protein. These behavioral changes of the protein occur in response to and in association with the pmf-driven activation of the protein and are reflected by a concomitant increase in ATP production at and $\mathrm{H}^{+}$conductance of its $\mathrm{CF}_{0}$ - and $\mathrm{CF}_{1}$-site, respectively (Ort and Oxborough 1992, Daisuke et al. 2016). The coupling between an electric field and variable fluorescence at low actinic intensities would predict that the regulatory function and in particular the changes in the conductance state of the $\mathrm{CF}_{0}$ channel of the protein come into expression in the light-on and-off kinetics of variable fluorescence. A high fluorescence yield of the antenna Chls would indicate a high pmf and strength of the associated electric field (potential) sensed by the $\mathrm{RC}$ and, according to the inverse relation between potential and conductance in a proton pump circuitry, a low proton conductance $g_{\mathrm{H}}^{\text {thyl }}$. A low conductance indicates a high fraction $\alpha$ of inactive $\mathrm{CF}_{0} \cdot \mathrm{F}_{1} \cdot$ ATPases with a closed $\mathrm{H}^{+}$-conducting $\mathrm{CF}_{0}$ channel. The decline (decrease) of $F_{\mathrm{v}}$ during the PSMT phase of the Kautsky induction in a 30-s pulse (Fig. 5) then would point to a significant decrease in the fraction $\alpha$ of nonactivated $\mathrm{CF}_{0} \cdot \mathrm{F}_{1}$ complexes caused by the pmf-driven transduction of the low-conductive (closed) $\mathrm{CF}_{0}$ channels into a high conductance (open) state.

The application of a light-dark protocol like the one presented here appears to be a useful means for getting more insight into the similarity between changes in the pattern of the $\mathrm{F}_{\mathrm{v}}$ decay in the dark during the $\mathrm{P}-\mathrm{S}$ induction phase and those predicted for that of the trans-membrane pmf in association with a change in the fraction of closed and open $\mathrm{CF}_{0}$ channels of the $\mathrm{CF}_{0} \cdot \mathrm{CF}_{1} \cdot$ ATPase. A validation of the hypothesis on the relationship awaits further dedicated experiments. Measurements of light-on and -off kinetics of the electrochromic band shift at $515 \mathrm{~nm}$ (P515) are expected to be a promising means. It has been proposed that the slow component thereof (originally called reaction 2), is responsive to changes in the ATPase activity (Peters et al. 1983, 1985) and even is a direct measure of the trans-membrane pmf (Kramer and Crofts 1989, Cruz et al. 2001, Klughammer et al. 2013). These experiments are hampered by the fact that possible contaminations with responses originating from electric fields other than the proton motive force and contributing to the P515 response so far cannot be excluded (Vredenberg 1997).

In the final stage of the revision of this manuscript a paper was (pre-)published online (Snellenburg et al. 2017) in which a four state parametric model for the kinetics of the nonphotochemical quenching in PSII is presented. It shows some similarities with the approach followed here, except for its application to PAM fluorometer protocols. However, their state model is hampered by the debatable assumption that the fluorescence yield of NPQunquenched open centers in so called V-chloroplasts isolated from $1 \mathrm{~h}$ dark-adapted spinach leaves is equal to $\mathrm{F}_{0}$, in the paper designated with $\emptyset_{\mathrm{ou}}^{\mathrm{PSII}, \mathrm{V}}$ and $\mathrm{VF}_{0}$, respectively. This assumption is at violence with our results. These show (Figs. 1,2) that at low actinic intensities where photochemical and electrochemical quenching is negligibly small and the majority, if not all, RCs remain in the open state whereas the fluorescence yield can rise towards a level close to $\mathrm{F}_{\mathrm{m}}$, i.e. in their terminology to the level $\emptyset_{\mathrm{ou}}^{\mathrm{PSII}, \mathrm{V}} \sim \mathrm{VF}_{\mathrm{M}}\left(>>\mathrm{VF}_{0}\right)$.

Open Access This article is distributed under the terms of the Creative Commons Attribution License which permits any use, distribution, and reproduction in any medium, provided the original author(s) and the source are credited.

\section{References}

Belyaeva N.E., Bulychev A.A., Riznichenko G.Y., Rubin A.B.: Thylakoid membrane model of the Chl $a$ fluorescence transient and P700 induction kinetics in plant leaves. - Photosynth. Res. 130: 491-515, 2016

Bulychev A.A., Vredenberg W.J.: Modulation of photosystem II chlorophyll fluorescence by electrogenic events generated by photosystem I. - Bioelectrochemistry 54: 157-168, 2001.
Cardol P., De Paepe R., Franck F. et al.: The onset of NPQ and $\Delta \mu \mathrm{H}^{+}$upon illumination of tobacco plants studied through the influence of mitochondrial electron transport. - BBABioenergetics 1797: 177-188, 2010.

Chylla R.A., Whitmarsh J.: Inactive photosystem II complexes in leaves turnover rate and quantitation. - Plant Physiol. 90: 765 $772,1989$. 
Cruz J.A., Sacksteder C.A., Kanazawa A., Kramer D.M.: Contribution of electric field $(\Delta \Psi)$ to steady-state transthylakoid proton motive force ( $\mathrm{pmf}$ ) in vitro and in vivo. Control of pmf parsing into $\Delta \varphi$ and $\Delta \mathrm{pH}$ by ionic strength. Biochemistry 40: 1226-1237, 2001.

Daisuke T., Amako K., Hashiguchi M. et al:: Chloroplastic ATPsynthase Functions as an $\mathrm{H}^{+}$-Gatekeeper to Prevent the Over-Reduction State in Photosystem I: $\mathrm{H}^{+}$-Efflux Management is Critical for the Regulation of $\Delta \mathrm{ph}$ across the Thylakoid Membranes. Abstract 5A.12 - In: $17^{\text {th }}$ International Congress Photosynthesis (PS17). Pp. 238. Maastricht 2016.

Ebenhöh O., Fucile G., Finazzi G. et al.: Short-term acclimation of the photosynthetic electron transfer to changing light: a mathematical model. - Philos. T. Roy. Soc. B 369: 20130223, 2014.

Harbinson J., Hedley C.L.: Changes in P-700 oxidation during the early stages of the induction of photosynthesis. - Plant Physiol. 103: 649-660, 1993.

Horton P., Ruban A.V., Walters R.G.: Regulation of light harvesting in green plants. - Annu. Rev. Plant Phys. 47: 655684, 1996

Johnson M.P., Ruban A.V.: Rethinking the existence of a steadystate $\Delta \Psi$ component of the proton motive force across plant thylakoid membranes. - Photosynth. Res. 119: 233-242, 2014.

Junge W.: Membrane potentials in photosynthesis. - Annu. Rev. Plant Physiol. 28: 503-536, 1977.

Kanazawa A., Kramer D.M.: In vivo modulation of nonphotochemical exciton quenching (NPQ) by regulation of the chloroplast ATP synthase. - P. Natl. Acad. Sci. USA 99: 12789-12794, 2002.

Ke B.: Photosynthesis photobiochemistry and photobiophysics. - In: Govindjee, Sharkey T.D (ed.).: Advances in Photosynthesis and Respiration, Vol. 10. Kluwer Acad. Publ., Dordrecht 2001.

Klughammer C., Siebke K., Schreiber U.: Continuous ECSindicated recording of the proton-motive charge flux in leaves. - Photosynth. Res. 117: 471-487, 2013.

Kramer D.M., Crofts A.R.: Activation of the chloroplast ATPase measured by the electrochromic shift in leaves of intact plants. - BBA-Bioenergetics 976: 28-41, 1989.

Lazár D., Schansker G.: Modeling of chlorophyll $a$ fluorescence transients. - In: Laisk A., Nedbal L., Govindjee (ed.): Photosynthesis in Silico: Understanding Complexity from Molecules to Ecosystems. Pp. 85-123, Springer, Dordrecht 2009.

Lazár D.: Parameters of photosynthetic energy partitioning. - J. Plant Physiol. 175: 131-147, 2015.

Lill H., Junge W.: $\mathrm{CF}_{0}$, the proton channel of chloroplast ATP synthase. - Eur. J. Biochem. 179: 459-467, 1989.

Niyogi K.K., Li X.-P., Rosenberg V., Jung H.-S.: Is PsbS the site of nonphotochemical quenching in photosynthesis? - J. Exp. Bot. 56: 375-382, 2005.

Ort D.R., Oxborough K.: In situ regulation of chloroplast coupling factor activity. - Plant Physiol. 43: 269-291, 1992.

Papageorgiou G.C., Govindjee: The nonphotochemical quenching of the electronically excited state of chlorophyll $a$ in plants: definitions, timelines, viewpoints, open questions. - In: Demmig-Adams B., Garab G., Adams W.W., Govindjee (ed.): Nonphotochemical Quenching and Energy Dissipation in Plants, Algae and Cyanobacteria. Advances in Photosynthesis and Respiration, Vol. 40, Pp. 1-44. Springer, Dordrecht 2014.

Papageorgiou G.C., Govindjee (ed.): Chlorophyll $a$ Fluorescence: a Signature of Photosynthesis, Advances in Photosynthesis and Respiration, Vol. 19, Springer, Dordrecht 2004.

Papageorgiou G.C., Tsimilli-Michael M., Stamatakis K.: The fast and slow kinetics of chlorophyll a fluorescence induction in plants, algae and cyanobacteria: a viewpoint. - Photosynth. Res. 94: 275-290, 2007.

Pascal A.A., Liu Z., Broess K., van Oort B. et al.: Molecular basis of photoprotection and control of photosynthetic lightharvesting. - Nature 436: 134-137, 2005.

Peters R.L.A., Bossen M., van Kooten O., Vredenberg W.J.: On the correlation between the activity of ATP-hydrolase and the kinetics of the flash-induced P515 electrochromic bandshift in spinach chloroplasts. - J. Bioenerg. Biomembr. 15: 335-346, 1983.

Peters R.L.A., van Kooten O., Vredenberg W.J.: The kinetics of the flash-induced P515 response in relation to the $\mathrm{H}^{+}$permeability of the membrane bound ATPase in spinach chloroplasts. - J. Bioenerg. Biomembr. 17: 207-316, 1985.

Schreiber U., Klughammer C.: Analysis of photosystem I donor and acceptor sides with a new type of online-deconvoluting kinetic LED-array spectrophotometer. - Plant Cell Physiol. 57: 1454-1467, 2016.

Shikanai T.: Regulatory network of proton motive force: contribution of cyclic transport around photosystem I. - Photosynth. Res. 129: 253-260, 2016.

Snellenburg J.J., Johnson M.P., Ruban A.V. et al.: A four state parametric model for the kinetics of the nonphotochemical quenching in Photosystem II. - BBA-Bioenergetics 1858: 854864, 2017.

Stirbet A., Govindjee: The slow phase of chlorophyll $a$ fluorescence induction in silico: Origin of the slow S-M fluorescence rise. - Photosynth. Res. 130: 193-213, 2016.

Stirbet A., Govindjee, Strasser B.J., Strasser R.J.: Chlorophyll a fluorescence induction in higher plants: Modeling and numerical simulation. - J. Theor. Biol. 193: 131-151, 1998.

Strasser R.J., Srivastava A., Govindjee,: Polyphasic chlorophyll $a$ fluorescence transient in plants and cyanobacteria. Photochem. Photobiol. 61: 32-42, 1995.

Takizawa K., Kanazawa A., Kramer D.: Depletion of stromal Pi induces high 'energy-dependent 'antenna exciton' quenching $\left(\mathrm{q}_{\mathrm{E}}\right)$ by decreasing proton conductivity at $\mathrm{CF}_{0}-\mathrm{CF}_{1}$ ATP synthase. - Plant Cell Environ. 31: 235-243, 2008.

Tikhonov A.N.: Induction events and short-term regulation of electron transport in chloroplasts: an overview. - Photosynth. Res. 125: 65-94 2015.

Tikkanen M., Aro E.A.: Integrative regulatory network of plant thylakoid energy transduction. - Trends Plant Sci. 19: 10-17, 2014.

van Grondelle R.: Excitation energy transfer, trapping and annihilation in photosynthetic systems. - BBA-Rev. Bioenerg. 811: 147-195, 1985.

Vredenberg W.J.: A three-state model for energy trapping and chlorophyll fluorescence in photosystem II incorporating radical pair recombination. - Biophys. J. 79: 26-38, 2000.

Vredenberg W.J.: Electrogenesis in the photosynthetic membrane: fields, facts and features. - Bioelectroch. Bioenerg. 44: $1-11,1997$.

Vredenberg W.J.: Kinetic analysis and mathematical modeling of primary photochemical and photoelectrochemical processes in plant photosystems. - Biosystems 103: 139-151, 2011.

Vredenberg W.J.: A simple routine for quantitative analysis of light and dark kinetics of photochemical and nonphotochemical quenching of chlorophyll fluorescence in intact leaves. - Photosynth. Res. 124: 87-106, 2015.

Vredenberg W.J., Prášil O.: Modeling of chlorophyll $a$ fluorescence kinetics in plant cells: derivation of a descriptive 
algorithm. - In: Laisk A, Nedbal L., Govindjee (ed.): Photosynthesis in Silico: Understanding Complexity from Molecules to Ecosystems. Pp. 125-149. Springer, Dordrecht 2009.

Vredenberg W.J., Bulychev A.A.: Photoelectrochemical control of the balance between cyclic- and linear electron transport in photosystem I. Algorithm for $\mathrm{P} 700^{+}$induction kinetics. - BBABioenergetics 1797: 1521-1532, 2010.

Vredenberg W.J., Durchan M., Prášil O.: On the chlorophyll $a$ fluorescence yield in chloroplasts upon excitation with twin turnover flashes (TTF) and high frequency flash trains. Photosynth. Res. 93: 183-192, 2007.

Vredenberg W.J., Durchan M., Prášil O.: The analysis of PSII photochemical activity using single and multi-turnover excitations. - J. Photoch. Photobio. B 107: 45-54, 2012.

Witt H.T.: Energy conversion in the functional membrane of photosynthesis. Analysis by light pulse and electric pulse methods: The central role of the electric field. - BBA-Rev. Bioenerg. 505: 355-427, 1979. 